\title{
The mental health of nurses in the UK
}

\section{Peter Nolan \& Maureen Smojkis}

\begin{abstract}
The recruitment and retention crisis in UK nursing puts many reforms outlined in recent health policies at risk. Increasing bureaucratisation of health care, unattractive working conditions, poor pay and the emotionally exhausting nature of the work are associated with high rates of burnout and workplace violence. Some nurses prefer agency work, some leave because they cannot reconcile a caring role with working in the NHS. It seems that health care has become emotionally distant and the profession's longstanding attachment to caring through interpersonal relationships has been overridden by a hightechnology, fast-track system of care management. To retain the principles and ethos of nursing at the centre of health developments, attention must be given to the micro-environments in which nurses work.
\end{abstract}

This is the third in a series of papers on the mental health of marginal groups. Previous papers have considered the effects of asylum-seeking and refugee status on mental health (Tribe, 2002) and the implications for psychiatric services in the UK of young refugees who have fled from chronic civilian strife (Hodes, 2002).

The Heathrow Debate (Department of Health, 1994) concluded that nursing, in whatever setting it is practised, draws on a tradition of caring and is based on both skills and values. The UKCentral Council's report Healthcare Futures (Warner et al, 1998) suggests that, in the next decades, nursing will be characterised by a high degree of technical competence and 'scientific rationality', while retaining its 'human' qualities and continuing to find the time to express them. Kitson (1996) had already foreseen a potential conflict in these requirements, and warned nurses that they would have to find ways of reconciling the technical aspects with the caring side of their work. The aim of this paper is to discuss how nurses are coping with this and other challenges posed by recent health care reforms.

Any attempt to assess the current state of nursing in the UK needs to take into account first, the relentless pace of change in health care over the past two decades and second, the fact that nurses are central to the provision of most services and are the largest professional group working in the health service (Edwards \& Hale, 1999). About 640000 nurses are entered on the UK professional nursing register, which was first established in 1921 following the Nurses' Act 1919. An estimated $78 \%$ of these nurses work with adults in general health care settings; $12 \%$ are working in a mental health context, $4 \%$ in learning disability, $2 \%$ in paediatric care and the remaining $4 \%$ are registered midwives or fever nurses (UK Central Council, 2000).
The sheer size and diversity of nursing militate against it being a unified discipline, but despite these differences a 1997 Department of Health White Paper is explicit that nurses have a central role to play in shaping and delivering modern health care services.

Nursing has altered considerably since Florence Nightingale defined it as 'a foot-soldier on the frontline in the battle against disease'. The scope of practice today is far beyond that of the 19th-century profession, as increasing numbers of nurses work outside hospitals in primary care and community settings, and are involved in home treatment and industry. Patterns of nursing regulation, education and training vary considerably across the world, although agreements within the European Union enable some movement of the nursing workforce across national boundaries. Once the envy of the world, the National Health Service (NHS) is now struggling to meet the needs and increasing expectations of a demanding public, and the effects of this struggle are frequently seen in those who deliver front-line services. It had long been assumed that nurses, because of the nature of their work, are able not only to recognise stress in and care for others, but also to monitor stress levels in themselves and devise and implement strategies to prevent deterioration of their own mental health. This now seems to be an unwarranted supposition.

In recent years, nursing appears to have become less attractive to young people as a career choice. A study commissioned by the Royal College of Nursing revealed that $22 \%$ of nurses were actively seeking alternative employment because of punishing shift patterns that allowed little time for social and home life, and bullying-style management (Royal College of

Peter Nolan is a professor of mental health nursing (Staffordshire University School of Health, Blackheath Lane, Stafford ST18 0AD, UK. E-mail: peter.nolan@staffs.ac.uk). His research interests centre on the observation of health professional teams to assist interservice collaboration. He is currently studying the integration of community mental health nurses into primary care teams. Maureen Smojkis is a lecturer and programme coordinator for the MA course in solution-focused brief therapy at the Centre for Lifelong Learning, University of Birmingham. She collaborates with the local mental health trust in the development of staff support schemes. Her particular interest is in the use of solution-focused interventions in reflective practice and team-building. 
Nursing, 2001). The problems posed by high rates of turnover of nursing staff and the associated costs are well recognised. The reasons why nurses leave the profession are complex, although significant factors appear to be dissatisfaction with management, lack of support from senior personnel, and a desire for increased autonomy and greater involvement in decision-making (Ames et al, 1992).

The increasingly bureaucratic nature of nursing, coupled with the Government's commitment to setting higher and higher national targets for services irrespective of resources at local level, are adding to the difficulties (Song et al, 1997). Decker (1997) found that the tendency to replace management by government directives, clinical and legal frameworks and financial constraints has undermined clinical leadership. Research shows that nurses, along with personnel in other large human service organisations, are faced with low wages, poor career opportunities, short-term contracts and susceptibility to mental health problems (Baba \& Jamal, 1991). It is perhaps not surprising that such conditions make it difficult to recruit and retain staff.

Prior to the publication of Making a Difference (Department of Health, 1999a), extensive consultation revealed unrest among nurses in relation to career structure, remuneration and the perceived absence of professional and clinical leadership. It was obvious that staff were no longer prepared to tolerate working conditions that formerly might have gone unchallenged. Long hours, unpaid overtime, having to accept patients regardless of whether the resources are available to care for them and lack of control over their work were found to be causes of dissatisfaction. Among the many recommended solutions to these problems were the improvement of education and training, extending the role of the nurse and the creation of a new role of 'nurse consultant'. It was argued that this post would strengthen clinical leadership, improve services and outcomes for patients and play a part in retaining experienced nurses who might otherwise leave the profession for more lucrative and satisfying employment elsewhere. The first wave of nurse consultants was appointed in 2000, with a second in 2001. However, a recent Report by the Comptroller and Auditor General (2001) states that the nursing shortage was probably worse than was previously estimated. The 'health professional workforce' was described as continuing to face significant staff shortages in such areas as nursing, midwifery, physiotherapy and radiography.

\section{Stress and ill health among nurses}

In 1999, the Government Statistical Service (Department of Health, 1999b) surveyed sickness, absence and violence in all 402 NHS trusts in the UK and found a $5.4 \%$ rate of sickness / absence among nurses that was second only to the $6 \%$ rate among ancillary staff. The rates for medical and administrative staff were $1.3 \%$ and $2.3 \%$, respectively. Nearly two-thirds of trusts $(60 \%)$ thought that sickness levels were a problem and $86 \%$ were actively involved in seeking ways of reducing these levels. Where records of the causes of absences were kept, it was found that the most common reasons for absence were respiratory illness (including colds and influenza) and musculoskeletal injuries. Less common were stomach upsets, headaches/migraine and non-specific, stress-related illnesses. Leiter \& Harvie (1996) found that mental health problems such as burnout and stress frequently manifest as physical conditions and, as a result, health care workers tend to report higher rates of physical disability than other occupational groups.

Focusing specifically on mental health problems, Borrill et al (1996) found that $28 \%$ of nurses in the NHS were suffering from minor mental health problems, generally identified as anxiety and depression. Similar findings were reported by Thomas (1997), who concluded that mental health problems were significantly correlated with increasing workload, understaffing, job insecurity and perpetual organisational change. So serious have nursing absence and sickness rates become that they were estimated in 1998 to be costing the NHS about $£ 700$ million annually (Williams et al, 1998).

Identifying the predisposing factors of mental health problems in nurses is of considerable interest worldwide. A Canadian study (Decker, 1997) found that job satisfaction and psychological distress of nurses in an urban university teaching hospital were significantly correlated with job security and the quality of relationships with seniors, colleagues, physicians and personnel from other units and departments. In the Caribbean, Vishwanath et al (1999) found that role conflict, work overload and lack of social support were predictors of stress, that burnout was the sole predictor of depression and that this in turn predicted both absenteeism and intention to leave the profession. The quality of the work environment, workload and physical fitness were found to affect job satisfaction of nurses in Finland (Nuika et al, 2000). This study concluded that the physical and mental demands of the job can be compensated for by staff-friendly work environments and supportive colleagues. In Germany Bussing \& Glaser (1999) found the well-being of nurses to be influenced by the degree of stress within the profession as a whole. When 'the system' was overstretched or challenged, individuals became emotionally exhausted and experienced feelings of depersonalisation.

Boey (1999) used Goldberg's General Health Questionnaire (GHQ) to study 'distressed' and 'stressresistant' nurses in Singapore. Stress-resistant nurses adapted to high levels of stress at work and remained mentally healthy. Their locus of control was internal 
and they exhibited higher self-esteem than the distressed nurses, who reported poor mental health status. Negative emotions as a means of coping were demonstrated less frequently by the stress-resistant nurses, who had greater support from family relationships. The study identified that the majority (79\%) of the nurses appeared to enjoy good mental health. Twenty-one per cent of Boey's sample reported four or more symptoms on the GHQ, and 12 were considered to have mild mental health problems.

It might be supposed that some clinical arenas are more stressful than others and lead to increased burnout among staff. However, Payne (2001) found that burnout among female hospice nurses in the UK was uncommon. The study concluded that the positive environment of the hospice more than compensates for the demanding nature of the work. Similarly, Lucas et al (1993) suggested that nurses working in intensive or critical care units were more satisfied with their jobs and less psychologically distressed than other nurses. The higher staffto-patient ratio and lower staff turnover in such units might contribute to a more positive work environment. Song et al (1997) found that greater job satisfaction and lower absenteeism rates could generally be achieved, even in situations where workload was high and emotionally demanding, when shared governance and a case-management practice model were adopted as working practices.

\section{Mental health nurses}

The provision of care for individuals with mental health problems has changed dramatically over the past decade. Along with the closure of psychiatric institutions, the role of mental health nurses underwent radical change, encompassing such areas as supporting and educating clients and their carers, as well as non-mental health care colleagues with whom they came into contact. Stress and coping in mental health nursing have been widely discussed because of the growing evidence that mental health workers are at high risk of mental illness, burnout and suicide (Nolan et al, 1999; Thomsen et al, 1999). The reasons for this are complex and poorly understood. It has been suggested that mental health work might attract a type of person who is predisposed to psychological distress, or the issue might be to do with the client group (Guppy \& Gutteridge, 1991).

McLeod (1995) found that working with people who have severe mental illnesses is extremely stressful, and much more transference and countertransference might be taking place between patients and inexperienced nursing staff than was thought possible. Margison (1987) hypothesised that psy- chiatrists become stressed because of role ambiguity, the complex organisational and structural aspects of their work and patients' negative perceptions of them. These issues, he argued, could equally apply to mental health nurses. Thomsen et al (1999), however, found that gender, level of self-esteem, the number and nature of the demands of home life, and the ability to devise and implement coping mechanisms were the significant indicators of nurses' mental health.

Prosser et al (1996) compared stress and coping strategies among hospital and community-based mental health nurses. Large numbers in both groups appeared to be experiencing emotional exhaustion due to the demands of their work. However, the hospital nurses were more detached from their patients and enjoyed a diminished sense of personal accomplishment compared with their colleagues in the community, who appeared to be significantly more satisfied with their work. Stress among the hospital-based nurses was most effectively reduced by social support, the source of which could be either professional or personal, or both.

Greenglass \& Burke's Canadian study (2000) examined the relationship between hospital restructuring and anger and hostility among nurses. Their results suggest that restructuring is a stressful and anger-provoking experience, and that stress and anger increase as restructuring initiatives proliferate. The more strongly individual nurses perceived that restructuring had lowered the quality of the care that they could provide and had negatively affected working conditions and staff morale, the more likely they were to experience depression, anxiety and somatisation. If nurses had a clear understanding of the hospital's future, they were less likely to have psychosomatic reactions, less likely to be angry and more likely to experience a sense of self-efficacy.

Most theorists assert that burnout is most likely to occur in the first year of practice (Cherniss, 1995). Edelwich \& Brodsky (1980), however, suggest that burnout can recur many times during the course of a career and that some professionals suffer a new episode after changing jobs.

\section{Violence and stress}

The increase in violent incidents in health care settings is a considerable concern. The Government Statistical Service (Department of Health, 1999b) found that, on average, 13 violent incidents per month were reported per trust in the UK. Violent incidents, including verbal abuse, were three times higher in mental health and learning disabilities settings than in other areas. The survey found that $64 \%$ of all incidents involved nursing staff, with an average of 11 violent incidents per 1000 nursing staff 
being reported each month, compared with 5 per 1000 non-nursing staff. Nearly all NHS trusts (96\%) had some form of violence reduction scheme in operation.

Violence against health care professionals is not confined to the UK. Soares et al (2000) examined the extent, nature and determinants of violence against mental health nurses and psychiatrists working in eight health care districts in Stockholm. They concluded that individuals do not need to be the primary victims of violence in order to experience its adverse effects. Fear of violence at work is associated with stress, anxiety and thoughts about leaving the organisation.

Comparing violence in mental health care in Sweden and England, Nolan et al (1999) found that English nurses encountered more violence in the course of their work than did their Swedish counterparts. Although the English nurses rated their organisational well-being more highly than the Swedish nurses, they experienced less robust individual well-being. They reported lower levels of self-esteem and felt that they shouldered a heavier workload than their Swedish counterparts.

Violence against health care staff has been found to have negative mental health consequences. Lanza (1996) argues that violence is associated with 'pathological and dysfunctional organisations', with overcrowded wards, budget cuts and poor working and patient environments, rather than with patient psychopathology.

\section{Defining nursing and its relationship to caring}

The importance of evidence-based practice and research in nursing has been supported by the educational curricula and the development of 'clinical nurse specialist' roles. The relevance and definition of 'care' and 'caring' in this brave new world are hotly debated. The debate is fuelled by a sense of unease on the part of nurses that their role needs clarification in a health care context where technical skills seem to be more eagerly sought than caring skills. Barker (2001) suggests that health care is becoming emotionally distant and that nursing's long-standing attachment to the concept of caring through interpersonal relationships has been superseded by the need to provide evidence of their utility within a post-positivist research paradigm. Because nursing/caring is frequently marginalised in health care strategy and planning, mental health nurses in particular have tried to validate their work by assuming the title of 'nurse therapist', thus acknowledging that nursing is often not perceived to be a therapeutic activity.

\section{Nurse education and student attrition}

There are wide variations in student attrition rates between institutions, but limited understanding as to the reasons. On average, $20 \%$ of nursing students in the school in which we work (17\% nationally, according to Hansard (2000)), and between $7 \%$ and $18 \%$ of students taking courses in professions allied to medicine fail to complete their programmes. Although these rates are comparable with those in other higher-education programmes, they represent a huge waste of resources.

To address these worrying figures, the Department of Health set a maximum of $13 \%$ for attrition from nursing and midwifery programmes and $10 \%$ from courses for other health professional students, starting from the September 2000 intake. The NHS Plan (Department of Health, 2000) has proposed a number of staffing initiatives, including an increase in student numbers to improve the supply of qualified staff. When the plan was drawn up, there were 50000 nurses and midwives, and 14000 therapists and scientists, on NHS-funded, pre-registration education and training programmes in England. The plan states that by 2004, a further 5500 nursing students and 4450 therapists and other health professional students will enter training each year.

\section{Discussion}

This brief overview of the literature reveals high levels of reported mental health problems among nurses, and mental health nurses in particular. This should be a reason for concern for both the Government and the nursing profession. A vigorous debate is required to establish underlying causes and possible solutions. One aspect of the debate might consider whether people who enter mental health nursing are innately vulnerable to mental ill health. It might also be that education raises unrealistic expectations of what can be achieved in mental health nursing, thereby predisposing nurses to disappointment, frustration and disillusionment. Working with clients who are unlikely to get better, who find it difficult to express their needs or their gratitude, may trigger a susceptibility to mental illness. If this is so, the debate might then consider whether screening of potential mental health nursing students should be carried out, and how this could be done. Research is required to investigate whether there are differences between male and female mental health nurses in their capacity to withstand the stresses of nursing, and whether education and training can minimise any differences or help nurses implement coping strategies more effectively. 
Increasing the numbers of nurses should reduce workload and thereby result in greater job satisfaction, less psychological distress and a lower turnover of staff. Shouldering a large case-load of clients might demoralise vulnerable staff when many clients have complex needs or require hospital beds that are not available. Referral for in-patient care needs to be made easier and faster, and case-loads reduced. In order to boost the number of those entering and returning to the profession, strategies such as the following should be implemented:

- appointment of recruitment officers, who can also improve retention rates

- making available 'back-to-nursing' events to promote nursing in a positive light

- provision of crèche facilities to enable nurses with young children to return to work

- flexible working hours to accommodate family life

- job rotation, job swaps, job shares and secondment opportunities, so that nurses can acquire new skills

- improved work environments

- more emphasis on assisting nursing staff to care for themselves

- better quality clinical supervision.

Nurses who experience mental health problems should not be removed from the workplace and advised to seek employment elsewhere. Instead, their support systems should be re-examined and strengthened. Management and senior nursing personnel have a critical role to play in supporting nurses as they grapple with restructuring of health care organisations and teams. Providing support for mental health nurses working in the community is not easy, and increased autonomy might not be sufficient compensation for increased isolation. Strategies for supporting community mental health nurses are urgently required, and should attract immediate funding.

Although pay and conditions will always be a potential focus for dissatisfaction, they are rarely the direct cause of people leaving a profession in which they feel valued and supported. Multiple new initiatives in the health service must be accompanied by consultation, or at least communication with those expected to implement them at the level of service delivery. Insecurity among nurses is a major cause of stress, low self-esteem and poor mental health, and can be addressed by keeping nurses, alongside other health professionals, fully informed about what is happening at their hospital or in their arena of work and how changes are likely to affect them. The issue of clinical mentoring and leadership is a key one in nursing. Nurses have repeatedly stated that they feel a void where professional and clinical leadership should be. It may be that nurse consultants can help to fill this void, provided that their job specification is such as to emphasise leadership and the provision of support to colleagues.

Nurses, and mental health nurses in particular, must examine their role and decide how it can be defined against the work of other carers so that they are seen to be providing a unique and essential service. Defining their role necessitates a reexamination of the concept of caring. Do nurses feel that it is sufficient for them to be carers or is it more important that they be technically competent? Is it possible to be both or does possessing technical skills mean that caring skills become devalued? Are nurses brave enough to leave the technical skills to others and reassert the centrality of caring in their profession?

Physical and mental ill health among mental health nurses, difficulties in recruitment and retention and violence in mental health care settings will continue to undermine the health service unless nurses' self-esteem is boosted by a far clearer sense of the nature and importance of the work they are undertaking. Only when nurses are cared for themselves - kept informed, and supported by strong professional and clinical leaders - are they in a position to take a caring paradigm into the work they are doing.

\section{References}

Ames, A., Adkins, S., Rutleddge, D., et al (1992) Assessing work retention issues. Journal of Nursing Administration, 22, 37-41.

Baba, V. V. \& Jamal, M. (1991) Routinisation of job context and job content as related to employees' quality of work. Psychology, 39, 94-102.

Barker, P. (2001) The Tidal Model: developing an empowering, person-centred approach to recovery within psychiatric and mental health nursing. Journal of Psychiatric and Mental Health Nursing, B, 6, 233-240.

Boey, K. W. (1999) Distressed and stress resistant nurses. Issues in Mental Health Nursing, 19, 33-54.

Borrill, C. S., Wall, T. D. \& West, M. A. (1996) Mental Health of the Workforce of the NHS Trusts, Phase 1: Final Report. Sheffield/Leeds: Institute of Work Psychology, University of Sheffield, and Department of Psychology, University of Leeds.

Bussing, A. \& Glaser, J. (1999) Work stressors in nursing in the course of redesign: implications for burnout and interactional stress. European Journal of Work and Organizational Psychology, 8, 401-426.

Cherniss, C. (1995) Beyond Burnout. London: Routledge.

Decker, F. H. (1997) Occupational and non-occupational factors in job satisfaction and psychological distress among nurses. Research in Nursing and Health, 20, 453-464.

Department of Health (1994) The Challenges of Nursing and Midwifery in the 21st Century (The Heathrow Debate). London: HMSO.

- (1997) The New NHS: Modern, Dependable. London: Stationery Office.

- (1999a) Making a Difference. London: Stationery Office.

- (1999b) Survey of Sickness, Accidents and Violence in NHS Trusts. Government Statistical Survey. London: Stationery Office. 
- (2000) The NHS Plan. London: Stationery Office.

Edelwich, J. \& Brodsky, A. (1980) Burn-out: Stages of Disillusionment in the Helping Professions. London: Human Sciences Press.

Edwards, M. \& Hale, N. (1999) Opportunities in a managerial age. In The Changing Nature of Nursing in a Managerial Age (eds I. Norman \& S. Cowley). Oxford: Blackwell Science.

Greenglass, E. R. \& Burke, R. J. (2000) The relationship between hospital restructuring, anger, hostility and psychosomatics in nurses. Journal of Community and Applied Social Psychology, 10, 155-161.

Guppy, A. \& Gutteridge, T. (1991) Job satisfaction and occupational stress. Work Stress, 5, 315-323.

Hansard (2002) Column 54W. Nov. 20.

Hodes, M. (2002) Implications for psychiatric services of chronic civilian strife: young refugees in the UK. Advances in Psychiatric treatment, 8, 366-374.

Kitson, A. L (1996) Does nursing have a future? BMJ, 349 1346-1442.

Lanza, M. L. (1996) Violence against nurses in hospital. In Violence on the Job - Identifying Risks and Developing Solutions (eds G. R. Vaden Bos \& E. Q. Butatao), pp. 56-72. Washington, DC: American Psychological Association.

Leiter, M. P. \& Harvie, P. L. (1996) Burnout among menta health workers: a review and a research agenda. International Journal of Social Psychiatry, 42, 90-101.

Lucas, M. D., Atwood, J. R. \& Hagaman, R. (1993) Replication and validation of anticipated turnover model for urban registered nurses. Nursing Research, 42, 29-35.

Margison, F. (1987) Stress in psychiatrists. In Stress in Health Professionals (eds R. Payne \& J. Firth-Cozens), pp. 72-88. Chichester: John Wiley \& Sons.

McLeod, T. (1995) Work stress among community psychiatric nurses. British Journal of Nursing, 6, 569-574.

Nolan, P., Dallender, J., Soares, J., et al (1999) Violence in mental health care: the experience of mental health nurses and psychiatrists. Journal of Advanced Nursing, 30, 934941.

Nuika, M., Paunonen, M., Hanninen, O., et al (2000) The nurse's workload in care situations. Journal of Advanced Nursing, 33, 406-415

Payne, N. (2001) Occupational stressors and coping as determinants of burnout in female hospice nurses. Journal of Advanced Nursing, 33, 396-405.

Prosser, D., Johnson, S., Kuipers, E., et al (1996) Mental health, 'burnout' and job satisfaction among hospital and community-based mental health staff. British Journal of Psychiatry, 169, 334-337.

Report by the Comptroller and Auditor General (2001) Educating and Training the Future Health Professional Workforce for England. London: Stationery Office.

Royal College of Nursing (2001) Shifting Patterns: A Guide to Employee-Friendly Working (code no. 001 500). London: RCN Publications.

Soares, J. F., Lawoko, S. \& Nolan, P. (2000) The nature, extent and determinants of violence against psychiatric personnel. Work and Stress, 14, 105-120.

Song, R., Daly, B. J., Rudy, E. B., et al (1997) Nurses' job satisfaction, absenteeism, and turnover after implementing a special care unit practice model. Research in Nursing and Health, 20, 443-452.

Thomas, B. (1997) Management strategies to tackle stress in mental health nursing. Mental Health Care, 1, 15-16.

Thomsen, S., Soares, J., Nolan, P., et al (1999) Feelings of professional fulfilment and exhaustion in mental health personnel. Psychotherapy and Psychosomatics, 68, 157-164.

Tribe, R. (2002) Mental health of refugees and asylumseekers. Advances in Psychiatric Treatment, 8, 240-248.

UK Central Council (2000) Analysis of Registered Qualifications on the Effective Register on 31st March 2000. London: UKCC.

Vishwanath, V., Baba, B., Galperin, L., et al (1999) Occupational mental health: a study of work related depression among nurses in the Caribbean. International Journal of Nursing Studies, 36, 163-169.
Warner, M, Longley, M., Gould, E., et al (UKCC) (1998) Healthcare Futures 2010. Glamorgan: Welsh Institute for Health and Social Care.

Williams, S., Mitchie, S. \& Pattini, S. (1998) Improving the Health of the NHS Workforce. London: Nuffield Trust.

\section{Multiple choice questions}

1 The UKCC has stated that tomorrow's nurses will:

a be better paid

b be technically competent

c shoulder larger case-loads

d demonstrate 'scientific rationality'

e demonstrate the 'human' qualities of caring.

2 The largest group of health professionals in the NHS are:

a doctors and medical secretaries

b doctors and research staff

c nurses

d midwives

a in professions allied to medicine.

3 Nurse consultants are intended to:

a negotiate for better pay and conditions for nurses

b strengthen clinical leadership

c work alongside doctors to determine appropriate care for patients

$\mathrm{d}$ play a part in retaining experienced nurses in the profession

e work with government in drafting new health care initiatives.

4 Burnout among hospice nurses and nurses working in intensive care is not common, owing to:

a high staff/patient ratios and low turnover of staff

b high public profile

c the case-management practice model

$\mathrm{d}$ better pay and working conditions for nurses

e better resources in hospices and intensive care units than in other areas of the NHS.

5 Violence against health care professionals has been found to be associated with:

a increased use of counsellors

b more litigation by staff against NHS trusts

c patient psychopathology

d stress, anxiety and thoughts about leaving the organisation

e budget cuts.

\section{MCQ answers}

\begin{tabular}{|c|c|c|c|c|}
\hline & 2 & 3 & 4 & 5 \\
\hline $\mathrm{F}$ & a F & a F & a $\mathrm{T}$ & a $F$ \\
\hline $\mathrm{T}$ & $\mathrm{b} F$ & b $\mathrm{T}$ & b $F$ & b F \\
\hline $\mathrm{F}$ & c $\mathrm{T}$ & C F & C $\mathrm{T}$ & \\
\hline $\mathrm{T}$ & d F & $\mathrm{d} T$ & $\mathrm{~d} F$ & \\
\hline $\mathrm{T}$ & e $F$ & e F & e $\mathrm{F}$ & . \\
\hline
\end{tabular}

